\title{
La aplicación de la función social de la propiedad intelectual a través del abuso del derecho: un análisis necesario para el sistema de derecho civil*

\author{
Application of Property's Social Function in Intellectual Property Rights Through Abuse of Law Principle: A \\ Necessary Analysis for Civil Law System
}

Felipe Arbouin-Gómez ${ }^{\text {a }}$

Pontificia Universidad Javeriana, Colombia

DOI: https://doi.org/10.11144/Javeriana.vj139.afsp

farbouin@javeriana.edu.co

ORCID: http://orcid.org/0000-0003-1298-0192

Juan camilo Contreras-Jaramillo

Pontificia Universidad Javeriana, Colombia

juancontreras@javeriana.edu.co

ORCID: http://orcid.org/0000-0001-7992-4211

Carlos Andrés Uribe-Piedrahita

Pontificia Universidad Javeriana, Colombia

uribecarlos@javeriana.edu.co

ORCID: http://orcid.org/0000-0002-0450-4340

\section{Resumen:}

En los sistemas de tradición civil, los límites a la propiedad intelectual suelen estar estructurados desde la perspectiva de las regulaciones generales y abstractas que el legislador ha prejuzgado como necesarias y pertinentes. Aunque reconocemos la importancia y utilidad de este tipo de decisiones normativas, también debemos señalar que las mismas pueden obviar escenarios particulares no incorporados en una norma de carácter general, o debido a sus características (temporales o modales) no pueden ser tenidos en cuenta al momento de crear el límite normativo. En este sentido, proponemos el uso de la figura del abuso del derecho como un eventual remedio para el ejercicio antisocial de derechos de propiedad intelectual. Para tal efecto, utilizaremos la función social de la propiedad intelectual como criterio para definir los casos en que el uso abusivo (contrario a los propósitos del derecho) puede ser determinado; siempre y cuando, la estructura teórica utilizada permita entender a la función social como un límite a la propiedad. En el caso contrario, el ejercicio antisocial de la propiedad intelectual deberá ser entendido simplemente como una violación al mismo derecho por parte de su titular. Finalmente, presentaremos el caso de una figura similar, el Misuse en propiedad intelectual, el cual ha servido para este mismo propósito en el sistema del common law.

Palabras clave: Propiedad intelectual, propiedad, abuso del derecho, función social, misuse.

\section{Abstract:}

In civil law systems, limits to intellectual property tend to be structured from a perspective of general and abstract regulations that lawmakers have previously judge as required and relevant. Although we recognize the importance and usefulness of this type of normative decisions, we must also admit that they can obviate particular aspects that are not incorporated in a general norm, or due to their characteristics, cannot be taken into account when creating the regulatory limit. In this sense, we propose the use of the law's abuse figure as a relevant remedy for an antisocial exercise of intellectual property rights. For this purpose, we will use property's social function as a criterion to define cases where abusive use (contrary to law's purposes) may be identified, as long as property's social function is understood as a limit to such rights. Finally, we will present the case of a similar figure, the Intellectual Property's Misuse, which has served the same purposes in the common law systems.

Keywords: Intellectual property, property, abuse of law, social function, misuse.

Notas de autor

\footnotetext{
${ }^{a}$ Autor de correspondencia. Correo electrónico: farbouin@javeriana.edu.co
} 


\section{Introducción: La relación entre la propiedad intelectual y el derecho de propiedad}

La flexibilización de los derechos de propiedad intelectual, es decir, la corriente que se opone al "maximalismo" ${ }^{[1]}$ o expansionismo de este tipo de derechos sobre bienes inmateriales, suele abrirse camino cuando otras áreas del derecho analizan una situación particular. Por ejemplo, cuando el derecho de la competencia analizó la forma en la que los titulares de patentes ejercían sus derechos cuando las mismas constituían estándares técnicos en una industria particular ${ }^{[2]}$. En este sentido, las consideraciones propias del derecho de la competencia llevaron a que las organizaciones de estándares ajustaran el ejercicio de sus derechos de cierta manera que resultaran otorgando licencias sobre sus patentes en condiciones justas, razonables y no discriminatorias ${ }^{[3]}$. El derecho de la competencia, en algunas jurisdicciones, también ha influido para que otro tipo de organización de titulares de derechos de propiedad intelectual, las sociedades (entidades) de gestión colectiva, ajusten el ejercicio de su derecho de autor o conexo y de esta manera evitar efectos anticompetitivos o restrictivos del mercado ${ }^{[4]}$.

El derecho de la competencia también ha contribuido a la flexibilización de los derechos de propiedad intelectual en casos donde se presenta una oposición entre el titular del derecho y la exclusión de la competencia en un mercado derivado o conexo al de su derecho, esto es, una limitación de la competencia en un mercado diferente al mercado propio, donde se comercializa el bien que incorpora el derecho ${ }^{[5]}$. Ejemplo de estos tipos de asuntos está en las decisiones de las autoridades de competencia sobre negativas a licenciar derechos de propiedad intelectual ${ }^{[6]}$, donde se ha considerado que el comportamiento será abusivo si se cumple un conjunto de criterios acumulativos: (a) que exista una negativa a contratar, (b) que la empresa que realiza la conducta tenga una posición dominante, (c) que la negativa obstaculice la aparición de un producto nuevo para el que existe una demanda potencial de los consumidores, (d) que carezca de justificación objetiva dicha negativa y, (e) que pueda excluir toda competencia en un mercado derivado.

En materia de derecho contractual, se han ajustado ciertas disposiciones que contrariaban las reglas generales en esta materia. Por ejemplo, cuando los jueces han determinado que los efectos de un contrato denominado "licencia" serán los de una enajenación, en la medida en que el contenido (normalmente extendido y dictado por el titular de derechos) evidencia una transferencia de un derecho a cambio de un precio único y no una simple autorización de uso limitada y temporal ${ }^{[7]}$.

Por el contrario, cuando la propiedad intelectual es vista desde la óptica del derecho de propiedad, la consecuencia parece alejarse de lo que hemos denominado como una flexibilización de estos derechos. En la mayoría de los casos, el vínculo con la propiedad se traduce en un énfasis en la posibilidad de control que tiene el titular de derechos sobre el bien inmaterial protegido (que se extiende a las copias del mismo). En este sentido, podemos referenciar algunas posiciones doctrinales en torno al muy discutido caso Oil States $^{[8]}$ en los Estados Unidos, las cuales plantean que las patentes, por ser un tipo de propiedad, cualquier intervención administrativa que pueda disminuir el poder exclusivo y excluyente del titular debe ser tomado como una expropiación ${ }^{[9]}$. Posición que encuentra eco en Colombia, específicamente en la Superintendencia de Industria y Comercio (la oficina de patentes local), que en una sesión de la Comisión Intersectorial de Propiedad Intelectual (CIPI), celebrada el 30 de marzo de 2016, afirmó lo siguiente ante la solicitud de declaratoria de interés público de la patente farmacéutica del medicamente IMATINIB:

"Ahora bien, si la concesión de la licencia obligatoria se realiza por razones de interés público, se estaría ante un escenario de expropiación por parte de la administración. De acuerdo con el artículo 58 de la Constitución Política, la expropiación requiere indemnización previa, pues una expropiación sin indemnización previa sólo está autorizada constitucionalmente en caso de guerra para atender los requerimientos de la misma." ${ }^{[10]}$ 
Esta misma tendencia se encuentra en el derecho de autor, en donde su equiparación o acercamiento al derecho de propiedad ordinaria, se ha dado para reforzar la idea de control (exclusivo y excluyente) que ostenta el titular de derechos sobre la obra. En este sentido, Zapata López se ha expresado así:

"La adopción de este concepto como expresión genérica para referirse a todo aquello que es propiedad del ingenio o del talento humano, implica para su titular, no debe olvidarse, un derecho de dominio, de exclusión y de ejercicio de derechos. Por ello cuando decimos en el derecho de autor es un derecho de monopolio, es porque un autor como García Márquez ejerce sobre su obra un monopolio: él determina las condiciones de tiempo y lugar en donde su obra debe ser utilizada, y además la remuneración que por esa utilización deba pagársele."[11]

Esta relación entre la propiedad intelectual y la propiedad ordinaria, en la que la primera encuentra argumentos para fortalecerse, también ha sido reconocida por los tribunales en Colombia, tal y como lo ha afirmado la Corte Constitucional:

"Los derechos patrimoniales de autor, en la concepción jurídica latina, son tantos como formas de utilización de la obra sean posibles, ellos no tienen más excepciones que las establecidas por la ley, pues las limitaciones han de ser específicas y taxativas."[12]

No obstante, consideramos que la lógica del derecho de propiedad no sirve exclusivamente para fortalecer y expandir el ámbito de protección de la propiedad intelectual. Tal entendimiento desconoce lo que significa el derecho de propiedad en los ordenamientos jurídicos modernos, en donde se ha incorporado, con toda claridad, una función social para este tipo de derechos subjetivos.

En este sentido, además, encontramos la figura del abuso del derecho de propiedad encaminada, precisamente, a moderar el ejercicio de los poderes del titular de derechos y que está enmarcada en el contexto de la función social de los mismos. De esta manera, a continuación, se analizará al abuso del derecho como una regla expost utilizada por el derecho civil, su relación con la función social de la propiedad y, finalmente, expondremos cómo el sistema del commonlaw ha empleado la figura del Misuse para alcanzar los mismos propósitos que le atribuimos al abuso del derecho para la propiedad intelectual en este artículo, en el contexto de la función social de la propiedad.

\section{Reglas ex ante y ex post en propiedad intelectual.}

En los sistemas de tradición civil, los límites ${ }^{[13]}$ a la propiedad intelectual son estructurados bajo reglas $e x$ ante, es decir, han sido codificados de forma general y abstracta para ser aplicados solo a las situaciones especialmente previstas en la norma. Los límites a la propiedad ordinaria también se preveían en este mismo sistema de tradición continental europea, lo cual explica, en alguna medida, por qué las posiciones maximalistas de la propiedad intelectual (o las posiciones de quienes no la comulgan con una mayor flexibilización) suelen estar soportadas en una estricta equiparación de los derechos de propiedad intelectual con una teoría tradicional de la propiedad ordinaria. De esta forma se obtiene la característica restringida y de interpretación limitada que estos límites tienen bajo esta perspectiva de derecho de propiedad.

En este punto, podemos señalar como ejemplos de reglas ex ante los límites consagrados en el ordenamiento jurídico colombiano para los "actos realizados exclusivamente con fines de enseñanza o de investigación científica o académica" ${ }^{\text {[14] }}$ que prevé el artículo 53 de la Decisión Andina 486 para las patentes. También en el artículo 22 de la decisión Andina 351 para las obras, plantea lo siguiente con respecto a los actos de reproducción

“por medios reprográficos para la enseñanza o para la realización de exámenes en instituciones educativas, en la medida justificada por el fin que se persiga, artículos lícitamente publicados en periódicos o colecciones periódicas, o breves extractos de obras lícitamente publicadas".[15] 
Incluso, algunas disposiciones en las que el supuesto de hecho resulta más detallado, como el artículo 157 de la Decisión Andina 486, que para las marcas establece que:

"El registro de la marca no confiere a su titular, el derecho de prohibir a un tercero usar la marca para anunciar, inclusive en publicidad comparativa, ofrecer en venta o indicar la existencia o disponibilidad de productos o servicios legítimamente marcados; o para indicar la compatibilidad o adecuación de piezas de recambio o de accesorios utilizables con los productos de la marca registrada, siempre que tal uso sea de buena fe, se limite al propósito de información al público y no sea susceptible de inducirlo a confusión sobre el origen empresarial de los productos o servicios respectivos" [16]

O el artículo 39 de la Ley 23 de 1982, que dispone:

"Será permitido reproducir por medio de pinturas, dibujos, fotografías o películas cinematográficas, las obras que estén colocadas de modo permanente en vías públicas, calles o plazas, y distribuir y comunicar públicamente dichas reproducciones u obras. En lo que se refiere a las obras de arquitectura esta disposición sólo es aplicable a su aspecto exterior." ${ }^{\text {[17] }}$

Sin embargo, como hemos mencionado anteriormente, este no es el único resultado posible de la asociación entre la propiedad intelectual y la racionalidad de la propiedad ordinaria. Existen principios y preceptos que siempre han acompañado a la propiedad ordinaria que abren el panorama de posibilidades al acercar su lógica con la de la propiedad intelectual, tal y como lo es el principio del abuso del derecho ${ }^{[18]}$.

\section{El abuso de los derechos de propiedad intelectual}

Las reglas ex post no resultan del todo extrañas a la tradición civilista de la propiedad, un ejemplo de ello es la figura del abuso del derecho. Esta es una regla de origen jurisprudencial ${ }^{[19]}$ mediante la cual el juez determinará, caso a caso, si es posible limitar el ejercicio de un derecho subjetivo cuando este es utilizado de forma anormal para el ordenamiento jurídico. Aunque en la evolución y el actual entendimiento de esta figura se pueden identificar diferencias en los presupuestos para su aplicación y las consecuencias derivadas de su ocurrencia (como puede ser la calificación del comportamiento del titular del derecho), es innegable su existencia y clasificación como regla expost para juzgar las consecuencias que comporta el ejercicio de derechos reconocidos en un sistema jurídico.

Debido a que excede los propósitos concretos del presente artículo, no estudiaremos la relación con el comportamiento subjetivo del titular del derecho (la existencia de un comportamiento culposo como habilitante para concluir que se abusó del derecho), o la calificación del principio como una fuente independiente de responsabilidad civil. Por el contrario, nos concentraremos en la característica invariable como remedio ex post, mediante el cual se pretende corregir un ejercicio disfuncional o antisocial ${ }^{[20]} \mathrm{de}$ un derecho, en un caso particular. En este sentido, la jurisprudencia ha reconocido explícitamente el reproche jurídico al ejercicio abusivo de derechos que, en principio, están legítimamente reconocidos en el ordenamiento ${ }^{[21]}$. Tal conclusión, además, ha trascendido el ámbito jurisprudencial y ha derivado en la consagración positiva de lo que podríamos llamar la prohibición de abusar de los propios derechos ${ }^{[22]}$.

A la propiedad intelectual, entendida como la relación jurídica entre un titular y ciertos bienes inmateriales ${ }^{[23]}$, le resulta aplicable en su totalidad esta prohibición general de ejercicio abusivo. En la medida en que, tal y como ocurre con el ejercicio del derecho de domino sobre bienes materiales, de prerrogativas contractuales o procesales y los derechos personalísimos, la propiedad intelectual al ser ejercida de manera anormal también podrá ser censurada o limitada, desviándose de su finalidad dentro del ordenamiento jurídico.

No obstante, debemos analizar con más detenimiento un aspecto que podría traer dificultades a la aplicación del abuso del derecho como un remedio expost de forma general y en especial al caso de los derechos de propiedad intelectual; esto es, el criterio para determinar cuándo un derecho se ejerció en desvío de su 
finalidad. Esta pregunta, que podría generar incertidumbre en la aplicación del principio de abuso del derecho, en nuestro concepto, encuentra respuesta en el ordenamiento constitucional colombiano, específicamente, en la función social de la propiedad.

Tal y como lo ha reconocido un amplio sector de la doctrina ${ }^{[24]}$, y también la jurisprudencia colombiana al entender a la propiedad intelectual como un tipo especial de propiedad ${ }^{[25]}$, resultan aplicables las reglas generales de la propiedad, incluyendo, por supuesto, aquellas de tipo constitucional, como lo es la función social de la propiedad.

\section{La teoría de la función social de la propiedad}

Para iniciar el análisis de la función social de la propiedad, debemos tomar como premisa que, en Colombia, el derecho real de propiedad se encuentra reconocido en la Constitución y en la ley como un derecho subjetivo de carácter patrimonial ${ }^{[26]}$ y que, tal y como lo ha afirmado la Corte Constitucional en repetidas ocasiones, no se trata de un derecho fundamental, sino que se enmarca dentro de la categoría de los derechos sociales, económicos o culturales. Solamente en los eventos en que con su vulneración o desconocimiento se pongan en riesgos derechos fundamentales, podrá ser defendido por vía de la acción constitucional de tutela. ${ }^{[27]}$

Así mismo, partiremos del hecho de que la propiedad no es un derecho absoluto, pues cuenta con limitaciones establecidas por el legislador en virtud del interés general y el derecho de otros ${ }^{[28]}$, es decir que, si bien la propiedad otorga a su titular los poderes de uso, disfrute y disposición sobre un bien tal y como señala el artículo 669 del Código Civil, su ejercicio no es ilimitado al haberse consagrado en la ley una serie de restricciones que condicionan su aprovechamiento.

Teniendo entonces que la propiedad privada se encuentra reconocida y constituye un derecho subjetivo patrimonial, a continuación, analizaremos en qué consiste la función social que la Constitución Nacional le asigna y cuáles son las principales maneras de entender dicha función.

Para comenzar, debemos señalar que el Acto Legislativo No. 1 de 1936 modificó la Constitución Nacional de 1886, señalando, entre otros, la referida función social de la propiedad, esto es, incluyendo el principio de solidaridad en el ejercicio del derecho referido, convirtiéndolo en un derecho que se ejerce en el interés particular de su titular, pero encaminado al bienestar común.

El principio de solidaridad — cuyos principios fueron recogidos por León Bourgeois en su obra Solidaridad-[29], que fue ampliamente definido por el Papa Juan Pablo II en su encíclica Sollicitudo rei socialis $^{[30]}$ y que ha sido varias veces definido por la Corte Constitucional, ${ }^{[31]}$ se entiende como aquella manera en que el Estado y los particulares deben ejercer sus determinados roles en la sociedad, al buscar el cumplimiento de los fines comunes; fines que se encuentran señalados en los artículos 1 y 2 de la Constitución Nacional y que corresponden al respeto de la dignidad humana, la prosperidad general, la convivencia pacífica y la vigencia de un orden justo. En particular y desde el punto de vista de las personas y los derechos subjetivos de los cuales son titulares, podemos entenderlo como la manera de ejercer los derechos, en interés y beneficio particular pero dirigido al cumplimiento de los fines de la colectividad. La persona, si bien tiene una serie de derechos subjetivos patrimoniales reconocidos y protegidos por el estado, debe ejercer esos derechos de manera tal que no solamente obtenga un beneficio propio, sino que su ejercicio aporte al bien común. El ejercicio de los derechos propios debe servir, como consecuencia, para el cumplimiento de los fines colectivos dirigidos al bienestar de la generalidad, al mejoramiento de la calidad de vida de todos los habitantes y la satisfacción adecuada de sus necesidades.

Después de haber definido el principio de solidaridad, fundamento de la consagración de la función social de la propiedad, a continuación, presentaremos las dos maneras en que dicha función puede entenderse en el ordenamiento colombiano, ya sea que se tome como una limitación a la propiedad o ya sea que se considere como una redelimitación o redefinición del este derecho. 
Hemos señalado ya que en Colombia la propiedad privada no es absoluta, pues está sometida a una serie de limitaciones que surgen como consecuencia de la prevalencia del interés general sobre el particular, es decir, de la necesidad de armonizar los diferentes intereses existentes para efectos de hacer posible la vida en comunidad. El ejercicio de los diferentes derechos subjetivos patrimoniales, por tanto, se encuentra restringido, ya sea por razones de interés general o como consecuencia de la necesidad de proteger los derechos particulares de otros individuos, lo que significa que el ejercicio de las facultades o potestades que estos otorgan a su titular no son ilimitados. Para el caso de los derechos reales y, particularmente, para el derecho de propiedad la ley le otorga al propietario de un bien el poder de usar, disfrutar y disponer del mismo, potestades que se encuentran restringidas según los límites que para cada tipo de bien establece la ley.

Dentro del régimen de las limitaciones a la propiedad ha surgido la primera — y más tradicional— forma de entender la función social de la propiedad, esto es, como una limitación al derecho de propiedad de carácter $\mathrm{u}$ origen constitucional. Bajo esta forma de entender la función social, encontramos que el derecho real de propiedad se encuentra limitado conforme al principio de solidaridad, pues el ejercicio de los poderes de uso, disfrute y disposición llega hasta el punto en el que entra en conflicto con los intereses de la colectividad, esto es, con los fines de la solidaridad.

Bajo esta premisa, el propietario de un bien puede usar, disfrutar y disponer libremente del mismo, siempre y cuando con su ejercicio no supere los diferentes límites impuestos por la ley o los fines constitucionales señalados por la función social. El titular que en ejercicio de sus derechos supere los límites establecidos estará violando la ley o, por lo menos, extralimitándose en el ejercicio de su derecho.

Esta primera postura — señalamos desde ya- permite defender la existencia del abuso del derecho temática central del presente artículo- como ejercicio abusivo y reprochable del derecho de propiedad y, específicamente, nos permite su aplicación para el caso particular de la propiedad intelectual. En este orden de ideas, bajo este escenario y conforme a lo señalado anteriormente, el abuso del derecho puede presentarse como un ejercicio disfuncional o antisocial de un derecho en un caso en particular, ejercicio que, no obstante, y de manera abstracta, se efectúa de manera formalmente ajustada a la ley.

Lo anterior significa que es posible presentar al abuso del derecho de propiedad como una consecuencia del desconocimiento de la función social de la misma, por tratarse dicha función de una limitación constitucional al derecho. Por tanto, cualquier violación que se presente a los fines constitucionales descritos mediante el uso, disfrute o disposición de un bien, podrá significar, en un caso concreto, un ejercicio antisocial del derecho. En consecuencia, y en el caso en que esto causare un daño a un tercero, daría cabida a la aplicación de la figura del abuso del derecho debido a la superación de los límites impuestos por la Constitución Nacional.

Bajo esta primera perspectiva, es decir, si tomamos a la función social de la propiedad como una limitación al ejercicio de los poderes otorgados por este derecho, la figura del abuso del derecho tendría plena cabida y, por tanto, sería plenamente aplicable al régimen de la propiedad intelectual.

No obstante, existe una segunda manera de entender a la función social de la propiedad, ya no como una limitación a la propiedad, sino como una redelimitación de la misma, es decir, como una redefinición de la manera cómo deben ejercerse los poderes concedidos por esta.

Como hemos señalado, la función social de los derechos obedece a la aplicación del principio de solidaridad en el ejercicio de los mismos. Esa solidaridad, que entendemos como la unión de intereses individuales armonizados entre sí y dirigidos al bien común, redefine los derechos subjetivos, es decir, redelimita su contenido dándoles un alcance no solamente individual sino invariablemente social, por lo que convierte a la función social de la propiedad no en una limitación a la propiedad, sino en una nueva manera en la que los poderes que esta otorga deben ser ejercidos.

Por lo anterior, y bajo la segunda postura, encontramos que una persona que es propietaria del bien, propiedad a la que la ley le otorga los poderes uso, disfrute y disposición, debe ejercerlos de acuerdo con el principio de solidaridad y siguiendo los fines de la colectividad, es decir, en beneficio - económico y personal - de su titular, pero en cumplimiento de los fines establecidos para el estado social de derecho. Bajo esta 
óptica, no se trata de una limitación al dominio: no es una restricción, un límite o barrera para ejercer los poderes que otorga la propiedad. De acuerdo con esta postura, la función social de la propiedad redelimita dichos poderes, les da un nuevo contenido, establece la manera en que el uso, goce y disposición deben ejercerse. En otras palabras, la función social de la propiedad no es un elemento externo que restringe el uso, disfrute o disposición del bien; la función social establece el contenido de los mismos y la manera como dichos poderes deben ejercerse y, por lo tanto, se convierte en un elemento de la estructura del derecho mismo.

Para los efectos estudiados en el presente artículo, el problema que esta postura genera es que, al tratarse la función social de una redelimitación constitucional al derecho, cualquier violación que se presentare a los fines constitucionales descritos mediante el uso, disfrute o disposición de un bien (material o inmaterial) no generaría un abuso del derecho sino una violación del mismo, como consecuencia del incumplimiento de los fines impuestos al derecho de propiedad por la constitución. Bajo esta óptica, no sería posible que el propietario de un bien ejerciera su derecho de manera antisocial o disfuncional y al mismo tiempo cumpliera con la función social. El ejercicio abusivo de un derecho conllevaría siempre el incumplimiento de los fines constitucionales y, por tanto, más que un abuso del derecho nos encontraríamos frente a un caso de violación del derecho de propiedad.

Entendiendo, entonces, a la función social de la propiedad como una redelimitación del derecho, podría afirmarse que la teoría del abuso del derecho por la violación de los fines impuestos por el principio de solidaridad no tendría cabida y, por lo tanto, no permitiría defender los postulados planteados en el presente artículo.

Sin embargo, a manera de conclusión sobre cualquiera de las dos ópticas presentadas, podemos señalar que la protección y reconocimiento a la propiedad privada está atada al cumplimiento de sus fines, es decir, condicionada al ejercicio del derecho conforme a los principios constitucionales señalados. Ya sea que entendamos a la función social como una limitación o como una redelimitación de la propiedad, en cualquiera de los dos casos su ejercicio en contra de los fines colectivos puede traer como consecuencia el desconocimiento del derecho por parte del Estado, tal y como ocurre con la extinción de dominio de tierras rurales incultas, ${ }^{[32]}$ con la extinción de dominio de bienes adquiridos o utilizados de manera ilícita ${ }^{[33]}$ y con la ya derogada extinción de dominio del suelo urbano, consagrada en el Capítulo VIII de la Ley 9 de 1989. ${ }^{34]}$ En otras palabras, el Estado reconocerá y protegerá el derecho de propiedad, siempre y cuando se ejerza de acuerdo con el contenido establecido para este derecho conforme al principio de solidaridad.

Asimismo, e igualmente bajo cualquiera de las posturas referidas, podemos señalar que la función social de la propiedad no es una obligación ni se convierte en una fuente de obligaciones para su titular, tal y como ha sido presentado, erróneamente en nuestro concepto, en algunas oportunidades por la jurisprudencia colombiana. ${ }^{[35]}$ La función social, reiteramos, consiste en una limitación o en la manera en que deben ejercerse los poderes del dominio, en cumplimiento de los fines de la colectividad, sin que ello signifique o genere ningún tipo de obligación o vínculo jurídico prestacional con alguna persona o personas determinadas. Por esta razón, el incumplimiento de la función social de la propiedad no trae como consecuencia el incumplimiento de una obligación con respecto a otro, ni otorga a sujeto alguno la posibilidad de exigir coactiva o judicialmente su cumplimiento. El incumplimiento de la función social, o más precisamente el ejercicio del derecho de propiedad en contravía de los principios constitucionales señalados, puede traer como consecuencia la aplicación de las sanciones que la constitución y la ley consagren - las cuales pueden llegar incluso hasta el desconocimiento mismo del derecho por parte del Estado-, pero en ningún caso constituye el incumplimiento de una obligación propiamente dicha.

Por tanto, la función social de la propiedad no es una obligación, ni un derecho-obligación, ni una carga o un deber. La propiedad en virtud de la función social no general obligaciones en favor de otras personas. Se trata de una limitación o de una redelimitación del derecho real de propiedad — según sea la postura que se adopte- que surge como consecuencia de la aplicación del principio de solidaridad a este derecho. 
Sin embargo, de la postura que se tome con respecto a la naturaleza jurídica de la función social de la propiedad dependerá la posibilidad o no de aplicar la teoría del abuso del derecho para el caso de ejercer los poderes otorgados por este, en contravía de los fines constitucionales impuestos al dominio por el principio de solidaridad. Es decir, ante el uso de la propiedad, contrario a la función social, se podrá utilizar uno u otro remedio - acción por abuso del derecho o violación del derecho mismo - dependiendo de la postura asumida según lo señalado con anterioridad.

\section{Aplicación de la función social al caso de la propiedad intelectual y su relación con el libre mercado}

Hemos afirmado que los derechos de propiedad intelectual, como derechos subjetivos reconocidos y protegidos en nuestro ordenamiento jurídico, también podrían ser ejercidos de manera abusiva, situación en donde será aplicable el principio de abuso del derecho como remedio ex post (caso a caso). Ante la pregunta de cuándo el ejercicio de un derecho de propiedad intelectual se ha desviado de su finalidad (¿cuándo existe abuso del derecho?), representando un uso disfuncional o antisocial, encontramos que el significado de la función social dará los criterios necesarios para responder tal cuestión. Un ejercicio de naturaleza similar se presenta en el desarrollo de la figura del misuse en los Estados Unidos.

En este sentido, al determinar el contenido del derecho subjetivo de propiedad (incluida la propiedad intelectual), la función social también servirá para determinar cuándo el ejercicio de estos derechos se ha desviado de ese significado constitucional. Así, como lo expuso Rengifo:

“(...) el acto será normal o abusivo, no por los motivos legítimos del agente, sino en tanto y en cuanto se encuentre en consonancia con los principios y valores axiológicos extraídos del texto constitucional o de la interpretación dada por la Corte Constitucional." [36]

La función social de los derechos de propiedad intelectual necesariamente contiene diferencias con la aplicación del mismo concepto en la propiedad ordinaria en la medida en que ésta última se fundamenta en la posesión material de la que carece la primera. De manera que los postulados de acceso a la propiedad no pueden ser los mismos que, por ejemplo, contiene una ley de reforma agraria. No obstante, como ya se ha expuesto en el apartado anterior, la función social está relacionada con la extensión del derecho, extensión que puede ser contraída a efectos de alcanzar los fines sociales constitucionalmente garantizados. Así pues, los derechos de propiedad intelectual también podrán ser contraídos cuando así lo demande la función social.

La Corte Constitucional ha dicho que:

"El preámbulo de la Constitución expresamente consagra como uno de sus fines asegurar la convivencia, la igualdad y la libertad dentro de un marco jurídico, democrático y participativo que garantice un orden político, social y económico justo. Esta finalidad no se podría alcanzar sin la cooperación activa de los particulares quienes son responsables por infringir la Constitución y las leyes y, además, por abusar de sus propios derechos, conducta ésta que de aceptarse como práctica social conduciría a la segura entronización de un orden injusto (CP art. 6). En una perspectiva dinámica, el ejercicio de los derechos constitucionales debe ser compatible con el respeto de los derechos ajenos. Se abusa de un derecho constitucional propio cuando su titular hace de él un uso inapropiado e irrazonable a la luz de su contenido esencial y de sus fines. En este orden de ideas, el abuso es patente cuando injustificadamente afecta otros derechos y, también, cuando su utilización desborda los límites materiales que el ordenamiento impone a la expansión natural del derecho, independientemente de que se produzca en este caso un daño a terceros." ${ }^{\text {[37] }}$

Esta garantía de un orden económico justo para nuestra constitución, entre otros factores como la función social, se implementará a través del mercado ${ }^{[38]}$, es decir, considerando equilibrios entre la capacidad de intervención del Estado y un modelo absolutista de mercado de naturaleza liberal clásica, esto es, dejando al Estado la capacidad de limitar tanto el poder público, como el poder privado, lo que se denomina como 
economía social de mercado. Bajo esta idea de mercado, el motor de la economía se cimienta en la empresa y la iniciativa privada bajo límites de raigambre constitucional, valiosos para la protección del interés general ${ }^{[39]}$.

La Corte Constitucional ha valorado este tipo de equilibrios, reservando parte de un determinado mercado o generando ventajas competitivas a determinados agentes públicos, con el fin de equilibrar los costos de desarrollar determinadas actividades económicas, al considerar que los agentes económicos privados no realizan las mismas actividades necesarias para el bienestar de las personas, pero que por ser poco rentables o no ser rentables en lo absoluto, se encuentra por fuera del objeto de los agentes privados y sí del Estado ${ }^{[40]}$.

La Superintendencia de Industria y Comercio, al evaluar comportamientos restrictivos de la competencia, también ha sopesado la relación entre derechos individuales (como la libertad de contratación) e intereses colectivos para determinar el alcance de sus intervenciones. En el asunto FEDEGAN (Resolución 40912 de 2012) ${ }^{[41]}$, la Superintendencia señala que la Federación de Ganaderos se negó a comprar a una empresa (LAVERLAM) sus productos (vacunas con antígeno importando) acudiendo a mecanismos artificiales, como que el producto fuera importando. Dicha justificación no es una razón objetiva para excluir a un agente del mercado.

De tal forma que cuando, en un caso particular, el ejercicio de un derecho de propiedad intelectual pueda ser juzgado como disfuncional o antisocial, en la medida en que contraríe la función social, materializado en la agresión del interés general o el libre mercado, se abrirá paso al remedio que brinda el principio de abuso del derecho para limitarlo.

El anterior entendimiento para la propiedad intelectual, para el caso del derecho privado colombiano, no es nuevo. Ya en 1960, la Corte Suprema de Justicia, ejerciendo las funciones de control constitucional que tenía para ese entonces y al analizar la constitucionalidad de un apartado del artículo 39 de la Ley 86 de 1946 que regulaba los precios que por uso de los derechos patrimoniales de autor se podrían cobrar a los usuarios, afirmó que:

"De consiguiente, cualquier norma legal que limite o desconozca para el titular de la propiedad intelectual la facultad de
disposición, o de la de uso, o de la de goce que le corresponde, sería contraria a la previsión contenida en el artículo 30 de
la Carta, a no ser que se tratara de los motivos de utilidad pública o de interés social (inciso $3^{\circ}$ del citado artículo); o de
la intervención del Estado en la explotación de la industrias o empresas públicas o privadas, con el fin de racionalizar la
producción, distribución y consumo de las riquezas" (resaltado fuera del texto). ${ }^{\text {[42] }}$

\section{Relación con la figura del Misuse de la propiedad intelectual}

El sistema de propiedad intelectual, al igual que otros campos del derecho donde el legislador otorga derechos subjetivos con fundamento en el desarrollo de principios, fines y valores superiores, contiene dispositivos internos para controlar el abuso de dichos derechos, en este caso del derecho de propiedad intelectual. En este caso, el dispositivo para el sistema del common law es la doctrina del misuse de un derecho de propiedad intelectual ${ }^{[43]}$. Esta doctrina, principalmente, está vinculada con ejercicios del derecho en el mercado que exceden el alcance del mismo, muy cercana a problemas de libre competencia, sin que se pueda predicar del misuse que, efectivamente, es una doctrina propia del derecho protector de la libre competencia. El misuse, entendiéndose como un término genérico que hace alusión a un abuso, en el contexto del derecho de la propiedad intelectual es, específicamente, un término que implica una institución de defensa contra el titular del derecho.

El término misuse es bastante amplio, su naturaleza se encuentra en su carácter de equidad ${ }^{[44]}$, esto es, mantener el ejercicio del derecho dentro las fronteras del derecho de propiedad intelectual concedido. En este sentido, la doctrina del misuse permite elecciones de política pública para juzgar aspectos como acceso y exclusividad ${ }^{[45]}$. 
Entre el derecho de la competencia y la doctrina del misuse existen importantes coincidencias como diferencias. Entre las coincidencias debemos señalar que ambos se relacionan con valoraciones de mercado, por ejemplo, el misuse de derechos de propiedad intelectual previene que el titular utilice su derecho para debilitar la competencia o para evitar que su titular expanda sus derechos más allá del ámbito de protección de las normas ${ }^{[46]}$. Una pregunta obvia sería: ¿por qué existe una doctrina del misuse si se relaciona con problemas de mercado para los que está pensado el derecho de la competencia? La respuesta podría tener dos consideraciones ${ }^{[47]}$. Por un lado, porque al ser una doctrina que se utiliza como defensa frente a un señalamiento de infracción a un derecho de propiedad intelectual, no genera en quien se defiende la necesidad de establecer el andamiaje probatorio que se requeriría en un caso de libre competencia y, por otro lado, permite aplicar una sanción diferente al titular del derecho como la no oponibilidad del derecho frente al sujeto al que se reclama la infracción del mismo ${ }^{[48]}$.

Entre las diferencias que pueden encontrarse entre el derecho de la competencia y la doctrina del misuse tenemos que la doctrina del misuse refleja una defensa afirmativa, es decir, quien invoca la doctrina del misuse se encuentra como demandado en una controversia de propiedad intelectual, mientras que el derecho de la competencia actúa como reproche frente una conducta, es decir, permite el ejercicio de acciones en contra de quien ejerce un derecho ${ }^{[49]}$. También es una diferencia la protección del dominio público, aún si el agente que realiza la conducta no tiene posición dominante, opera la defensa en contra de una demanda por violación de un derecho de propiedad intelectual, esto es, no se requiere que el sujeto que realiza la conducta sea un sujeto calificado. Otra diferencia es que la doctrina del misuse busca que no se pueda oponer el derecho propiedad intelectual en su contra, mientras que el derecho de la competencia pretende el establecimiento de sanciones o perjuicios en contra del agente acusado o demandado ${ }^{[50]}$.

La doctrina del misuse primero fue aplicada en asuntos de patentes y, años después, se extendió a los derechos de autor (copyrights). El primer asunto al que se aplicó la doctrina del misuse en Estados Unidos fue el caso MotionPicture Patents de $1917^{[51]}$. En este caso, el titular de una patente, que consistía en un mecanismo que permitía pasar los rollos de películas en a través de los proyectores de películas de cine, se negó a licenciar la patente a menos que se aceptara la condición de que todos los proyectores tendrían una advertencia que prohibía el uso de cualquier película que no fuera manufacturada por el titular de la patente. En este sentido, el titular de la patente busco utilizar su patente para controlar el mercado de la venta de películas, mercado que no se encontraba cubierto por dicha patente.

“[...] estamos convencidos de que el derecho exclusivo otorgado en cada patente debe limitarse a la invención descrita en las reivindicaciones de la patente, y no es competencia del titular de una patente, mediante notificación adjunta a su máquina, ampliar el alcance de su monopolio de patentes al restringir el uso de la misma a materiales necesarios para su funcionamiento, pero que no son parte de la invención patentada $[\ldots]^{p[52]}$

La Corte expresa que la recompensa al inventor se debe basar enteramente en su invención y, por lo tanto, no se debe permitir que por medio instrumentos jurídicos el inventor extienda el alcance de su derecho, imponiendo cargas de forma injusta sobre la sociedad ${ }^{[53]}$. El potencial problema de haber permitido esta extensión del derecho de patentes hubiese sido las consecuencias negativas en el mercado de películas, disminuyendo la oferta de dichos bienes y limitando el bienestar de los consumidores. Considerando esto, el problema tendría efectos tanto en la innovación, como en la competencia ${ }^{[54]}$.

Presentada la intervención de la Corte, debemos precisar que, si bien la decisión tiene un contenido de afectación de la competencia en el mercado, la sentencia no toma en cuenta las normas de libre competencia en sus análisis. La Corte niega dar algún reconocimiento de la restricción realizada por MotionPicture Patents, aseverando que la restricción impuesta en la limitación del uso del bien objeto de la patente con películas que fueran exclusivamente de su propiedad opera como una restricción posventa en el uso del bien patentado. La Corte en su análisis se opone a la posición del Juez Holmes en su disentimiento, donde señalaba qué si el 
titular de una patente puede negarse a licenciar de forma absoluta el bien patentado, también puede licenciar dicho bien bajo cualquier limitación que considere. Siendo así, el Juez Holmes consideraba que cualquier violación de los términos del contrato por medio del cual se licencia el bien protegido constituía una violación de su derecho de propiedad intelectual.

\begin{abstract}
"supongo que un titular de una patente no tiene menos derecho de propiedad en su máquina patentada que cualquier otro propietario, y que, en adición a tener la máquina para sí mismo, la patente le otorga el derecho adicional de prohibir que el resto del mundo hagan lo que deseen con su derecho. En resumen, el titular del derecho puede por cualquier motivo, mantener su dispositivo completamente fuera del uso. [...] No siendo refutado lo anterior, no puedo entender por qué no puede dejar fuera del uso la maquinaria patentada, a menos que el titular de la licencia o, para el caso, el comprador, use bienes no protegidos con patentes en conjunto con el bien patentado. En términos generales, la medida de una condición es la consecuencia de una violación, y si esa consecuencia es una que el propietario puede imponer incondicionalmente, puede imponerla condicionalmente en un determinado evento. Non debet, cui plus licet, quod minus est non licere. (Al que le es lícito lo más no debe serle ilícito lo que es menos (Ulpiano: Digesto 50, 17, 21).”[55]
\end{abstract}

La visión del Juez Holmes fundamentada en el proverbio jurídico de "quién puede lo más, puede lo menos" deja de lado evaluaciones o ponderaciones específicas sobre el alcance de los derechos. En esencia, este marco reconoce que se es titular de un derecho y que el mismo puede oponerse ante todos (erga omnes), esto es, no hace daño a nadie sino el que hizo lo que no tiene derecho a hacer (qui iure suo utitur neminem laedit), supondría no reconocer que los derechos tienen límites. En línea con lo señalado y considerando a nuestra Corte Suprema, podemos enmarcar el disentimiento del Juez Holmes en clave de abuso del derecho. Así, sostuvo nuestra Corte, qué:

"[La] tesis del abuso representa, pues, una respuesta de avanzada frente a la tendencia que consideró los derechos desde una
marcada perspectiva individual y egoísta, fruto del formalismo legal y del absolutismo jurídicos reinantes, de manera que con
ella los derechos comenzaron a adquirir una connotación y un significado claramente sociales, impregnados de un carácter
solidario ajeno a aquella visión existente en un principio" ${ }^{[56]}$.

Ha continuado la Corte precisa sobre el abuso del derecho que:

“[la] ilicitud originada por el 'abuso' puede manifestarse de manera subjetiva -cuando existe en el agente la definida intención de agraviar un interés ajeno, o no le asiste un fin serio y legítimo en su proceder- o bajo forma objetiva cuando la lesión proviene del exceso o anormalidad en el ejercicio de determinada facultad, vista la finalidad para la cual fue esta última incorporada y reconocida en el ordenamiento positivo" ${ }^{57]}$

Haciendo eco de nuestra Corte Suprema, las normas deben actualizarse a las nuevas realidades, acudiendo a los principios generales, considerando la relatividad de los derechos, y pasando de interpretaciones literales de los textos legales a una hermenéutica funcional que reconozca principios y valores. Además, debe comprender los derechos subjetivos como derechos que son dados para la sociedad a la cual sirven, más que al individuo, esto es, los derechos subjetivos cómo derechos relativos y no absolutos. En este sentido, la Corte reconoce que, consecuentemente los derechos deben ejercitarse dentro del marco de la respectiva institución acorde con el espíritu que los inspira.

Motion Picture Patents es reconocido como el caso fundante de la doctrina del misuse en los Estados Unidos, donde queda claro, en la decisión, que todo análisis de los hechos fue considerado dentro del marco de la regulación del derecho de patentes que otorga la propiedad inmaterial, sin necesidad de acudir a otra legislación. Del análisis de la Corte se desprenden dos requerimientos utilizados en la valoración del misuse. En primer lugar, el hecho de que el titular de una patente pretende controlar el bien objeto de protección más allá de los límites que le fueron establecidos en el reconocimiento de su derecho y, en segundo lugar, el hecho de que si se autoriza el ejercicio del derecho más allá de sus límites, dicha práctica permitiría crear un poder de mercado en un producto secundario no protegido por su derecho de patente ${ }^{[58]}$.

Posterior a Motion Picture Patents, la Corte Suprema de los Estados Unidos, y con fundamento en dicho asunto, encontró en diferentes oportunidades en donde el titular de una patente vinculaba la venta de dichos 
bienes con bienes no patentados. Por ejemplo, en el asunto Carbice, DryIce Corporation fungiendo como el titular de una patente sobre usados para el transporte de bienes refrigerados, efectuó la vinculación entre el bien patentado y el no patentado en ambas direcciones, vinculó el uso de hielo seco al uso de los contenedores producidos por ella bajo patente, como también vinculó al uso de sus contenedores la obligación de usar el hielo seco producido por ella. Una empresa competidora en el mercado del hielo seco, Carbice Corporation, que vendía hielo seco a los consumidores de Dry Ice, bajo el conocimiento de la cláusula que vinculaba el uso de los contenedores con el hielo seco producido por dicha compañía, apareció en escena y concretó negocios, no obstante, ello implicaba que esos clientes utilizarían los contenedores sin el hielo producido por Dry Ice. DryIce demandó a Carbice por contribuir a la infracción de su patente; sin embargo, la Corte sostuvo, con fundamento en el asunto Motion Pictures Pstents, que el titular de una patente no puede extender el alcance de la misma a otros productos no protegidos por dicha patente con el fin de obtener beneficios como si dichos bienes tuvieran esa misma protección.

\begin{abstract}
"Si un monopolio pudiera expandirse tanto, el propietario de una patente para un producto posiblemente podría monopolizar el mercado en una gran parte de los materiales no patentados que se utilizan en su fabricación. El propietario de una patente para una máquina podría de ese modo asegurar un monopolio parcial sobre los suministros que se consumen en la operación de la máquina y que no están patentados. El titular de una patente para un proceso podría garantizar un monopolio parcial sobre el material que se emplea en este y que no tiene patente" ${ }^{\text {[59] }}$. [...] "El control sobre el suministro [de un] material no patentado está más allá del alcance del monopolio del titular de la patente. [...] Dry Ice Corp. está intentando, por fuera del derecho, emplear la patente para garantizar un monopolio sobre el material no patentado utilizado en el bien que incorpora la patente. El presente intento es análogo al uso de una patente como instrumento para restringir el mercado como fue reprochado por la Ley Antimonopolio Sherman Act" ${ }^{\text {"60] }}$.
\end{abstract}

La Corte Suprema, para este momento, tampoco señalaba la existencia de una doctrina denominada misuse, además, reconocía que los efectos de la extensión de un derecho de patentes a bienes o servicios que no tenían dicha protección por medio de alcances contractuales era análogo a la visión que imponía las normas de libre competencia. Sin embargo, concentraba el análisis al propio derecho de patentes, indicando que el problema se encontraba en el uso de un derecho más allá de sus fronteras ${ }^{[61]}$.

La evaluación moderna de la doctrina del misuse fue desarrollada en el asunto Morton Salt, donde la Corte, además, consideró que no se puede reconocer una demanda por contribución a la violación de un derecho de propiedad cuando el titular del derecho pretende extender su derecho a otros bienes que no ostentan la misma protección de la propiedad intelectual. Sin embargo, este asunto impuso otras cargas sobre el titular del derecho; sostuvo que el dicho titular no puede siquiera demandar por una infracción directa a su derecho cuando vincula otros bienes o servicios a los bienes patentados.

\title{
Conclusiones
}

De acuerdo con lo que se ha expuesto anteriormente, la racionalidad y estructura que ofrece el derecho de propiedad ordinaria no equivale a la inflexibilidad de tal derecho subjetivo. En este sentido, cuando se utiliza esta estructura para defender posiciones maximalistas en la propiedad intelectual, se está dejando de lado que la protección y reconocimiento a la propiedad privada está atada al cumplimiento de sus fines, es decir, condicionada al ejercicio de la misma conforme a su función social.

El incumplimiento de la función social o, más precisamente, el ejercicio del derecho de propiedad en contravía de los principios constitucionales señalados puede traer como consecuencia la aplicación de las sanciones que la constitución y la ley consagren. En este sentido, el abuso del derecho de propiedad (incluida la propiedad intelectual) aparece como un remedio ex post que presenta la misma estructura tradicional del derecho de propiedad para corregir un ejercicio disfuncional o antisocial de un derecho, en un caso particular; 
es decir, aquellos usos contrarios al significado constitucional del derecho de propiedad, contrarios a los fines de la colectividad.

Sin embargo, es importante aclarar con el objeto de dejar planteado el interrogante, que esta propuesta podrá defenderse sin mayores dificultades en el caso en que tomemos a la función social de la propiedad como una limitación al derecho. Diversas dificultades teóricas traerá defender dicha posición dentro de otras visiones, como por ejemplo, bajo aquella que cataloga a la función social como una redelimitación a la propiedad, caso en el cual la aplicación de la teoría del abuso del derecho por violación a los fines impuestos a la propiedad por la constitución parecería incompatible con la figura misma de la función social; lo que habilitaría, consecuentemente, las acciones correspondientes a una violación del derecho de propiedad por parte de su titular.

Ahora bien, los efectos del uso de un remedio expost, como lo es la figura del abuso del derecho en el sistema de propiedad intelectual, puede ser comprobado con el recuento del uso de una figura similar como lo es el misuse propio del comonlaw. La aplicación exitosa de este remedio, cuyos propósitos, al igual que en el abuso del derecho, están encaminados a defender a los terceros del ejercicio excesivo y antisocial de un derecho de propiedad intelectual, sirve como espejo de la utilidad que traería para el sistema del derecho civil la aplicación del abuso del derecho (fundamentado en la función social de la propiedad) en aquellos casos en los que los efectos del ejercicio de las facultades de un titular de derechos de propiedad intelectual exceda o contraríe la función social expresada en el libre mercado, el bien común o la solidaridad.

\section{Bibliografía}

Adam Mossoff, Statutes, common-law rights, and the mistaken classification of patents as public rights, 104 Iowa Law Review, n. ${ }^{\circ}$ 5, 2591-2616. https://ilr.law.uiowa.edu/assets/Uploads/E11-Mossoff.pdf

Ángel García Vidal, El material vegetal protegido por una patente o un derecho de obtentor y el empleo del producto de su cosecha con fines de propagación: agotamiento y privilegio del agricultor en Europa y en los EE.UU., 8 Cuadernos de Derecho Transnacional, n. ${ }^{\circ}$ 1, 76-100 (2016). https://e-revistas.uc3m.es/index.php/CDT/article/view/302 $0 / 1726$

Carbice Corp. vs. Patents Development Corp., 283 U.S. 27 (1931).

Carl Shapiro \& David Teece, Systems Competition and Aftermarkets: An Economic Analysis of "Kodak", 39 The Antitrust Bulletin, n. ${ }^{\circ} 1,135-162$ (1994). http://dx.doi.org/10.1177/0003603X9403900104

Carl Shapiro, Aftermarkets and consumer welfare: making sense of Kodak, 63 Antitrust Law Journal, n. 2, 483-511 (1995). https://www.jstor.org/stable/40843290

Carlos Andrés Uribe Piedrahita \& Fernando Carbajo Cascón, Regulación "ex ante" y control "ex post": la difícil relación entre propiedad intelectual y derecho de la competencia, Actas de derecho industrial y derecho de autor, n. 33 , 307-330 (2012-2013).

Carlos Andrés Uribe Piedrahita, Cuestiones concurrenciales y marcarias en la distribución de piezas de recambio (la problemática de los "aftermarkets"), en Marcas y distribución comercial 213-268 (Eduardo Galán Corona \& Fernando Carbajo Cascón coords., 2011).

Carlos Andrés Uribe Piedrahita, El poder de mercado en los aftermarkets: Consideraciones sobre la política de competencia en los mercados secundarios, Revista de derecho de la competencia y la distribución, n. . 10, 129-160 (2012)

Carlos Andrés Uribe Piedrahita, La innovación subsiguiente como limite económico para la valoración del comportamiento de abuso de posición dominante relacionado con las negativas a contratar o licenciar, Vniversitas, $\mathrm{n}$. ○ 126, 269-298 (2013). https://revistas.javeriana.edu.co/index.php/vnijuri/article/view/6128

Carlos Ignacio Jaramillo, El 'abuso del derecho' y su proyección en los ámbitos sustancial y procesal civil: perfiles de la conducta abusiva e inobservancia del deber de obrar de buena fe, Ed. Pontificia Universidad Javeriana \& Ibáñez (2019). 
Christina Bohannan \& Herbert Hovenkamp, Creation without restraint. Promoting liberty and rivalry in innovation, Oxford University Press (2012).

Código de Comercio Colombiano [CCoC]. Decreto 410 de 1971. Art. 830. 27 de marzo de 1971 (Colombia).

Constitución Política de Colombia [Const]. Art. 95.7 de julio de 1991 (Colombia).

Corte Constitucional de Colombia. Sentencia C-006 de 1993 (M. P. Eduardo Cifuentes Muñoz; 18 de enero de 1993).

Corte Constitucional de Colombia. Sentencia C-1054 de 2004 (M. P. Marco Gerardo Monroy Cabra; 26 de octubre de 2004).

Corte Constitucional de Colombia. Sentencia C-1231 de 2005 (M. P. Manuel José Cepeda Espinosa; 29 de noviembre de 2005).

Corte Constitucional de Colombia. Sentencia C-148-15 de 2015 (M. P. Gloria Stella Ortiz-Delgado; 7 de abril de 2015).

Corte Constitucional de Colombia. Sentencia C-228 de 2010 (M. P. Luis Ernesto Vargas Silva; 24 de marzo de 2010).

Corte Constitucional de Colombia. Sentencia C-276 de 1996 (M. P. Julio Cesar Ortiz; 20 de junio de 1996).

Corte Constitucional de Colombia. Sentencia C-334-93 de 1993 (M. P. Alejandro Martínez-Caballero; 12 de agosto de 1993).

Corte Constitucional de Colombia. Sentencia C-428 de 2007 (M. P. Jose Gregorio Hernández Galindo, Alejandro Martinez Caballero y Vladimiro Naranjo Mesa).

Corte Constitucional de Colombia. Sentencia C-595 de 1999 (M. P. Carlos Gaviria Díaz; 18 de agosto de 1999).

Corte Constitucional de Colombia. Sentencia C-666 de 2010 (M. P. Humberto Antonio Sierra Porto; 30 de agosto de 2010).

Corte Constitucional de Colombia. Sentencia C-830 de 2010 (M. P. Luis Ernesto Vargas Silva; 20 de octubre de 2010).

Corte Constitucional de Colombia. Sentencia C-978 de 2010 (M. P. Luis Ernesto Vargas Silva; 1ro de diciembre de 2010).

Corte Constitucional de Colombia. Sentencia C-992 de 2006 (M. P. Álvaro Tafur Galvis; 29 de noviembre de 2006).

Corte Constitucional de Colombia. Sentencia T-016 de 2009 (M. P. Jaime Córdoba Triviño; 23 de enero de 2009).

Corte Constitucional de Colombia. Sentencia T-073 de 1998 (M. P. Vladimiro Naranjo Mesa; 9 de marzo de 1998).

Corte Constitucional de Colombia. Sentencia T-413 de 1997 (M. P. José Gregorio Hernández Galindo; 28 de agosto de 1997).

Corte Constitucional de Colombia. Sentencia T-431 del 30 de septiembre de 1994 (M. P. José Gregorio Hernández Galindo; 30 de septiembre de 1994).

Corte Constitucional de Colombia. Sentencia T-434 de 2002 (M. P. Rodrigo Escobar Gil; 30 de mayo de 2002).

Corte Constitucional de Colombia. Sentencia T-506 de 1992 (M. P. Ciro Angarita Barón; 22 de agosto de 1992).

Corte Constitucional de Colombia. Sentencia T-511 de 1993 (M. P. Eduardo Cifuentes Muñoz; del 8 de noviembre de 1993).

Corte Constitucional de Colombia. Sentencia T-533 de 1992 (M. P. Eduardo Cifuentes Muñoz; 23 de septiembre de 1992).

Corte Constitucional de Colombia. Sentencia T-550 de 1994 (M. P. José Gregorio Hernández Galindo; 2 de diciembre de 1994).

Corte Constitucional de Colombia. Sentencia T-554 de 1998 (M. P. Fabio Morón Díaz; 5 de octubre de 1998).

Corte Constitucional de Colombia. Sentencia T-801 de 1998 (M. P. Eduardo Cifuentes Muñoz; 16 de diciembre de 1998).

Corte Constitucional de Colombia. Sentencia T-947 de 2001 (M. P. Manuel José Cepeda Espinosa; 4 de septiembre de 2001).

Corte Suprema de Justicia de Colombia. Sala de Casación Civil. Sentencia de fecha 6 de diciembre de 1899, Gaceta Judicial Año 15, 8. 
Corte Suprema de Justicia de Colombia. Sala de casación civil. Sentencia de 15 de noviembre de 2013. M. P. Arturo Solarte Rodríguez.

Corte Suprema de Justicia de Colombia. Sala de casación civil. Sentencia de 16 de septiembre de 2010. M. P. César Julio Valencia Copete.

Corte Suprema de Justicia de Colombia. Sala de casación civil. Sentencia 125 de 1994. M. P. Carlos Esteban Jaramillo Schloss; 19 de octubre de 1994).

Corte Suprema de Justicia de Colombia. Sala de Negocios Generales. Sentencia de fecha 6 de mayo de 1927, Gaceta Judicial, año 34, 264.

Corte Suprema de Justicia de Colombia. Sala plena. Sentencia de fecha 10 de marzo de 1938, M. P. Hernán Guillermo Aldana Duque, 140.

Corte Suprema de Justicia de Colombia. Sala Plena. Sentencia del 10 de febrero de 1960, M. P. Humberto Barrera Domínguez.

Corte Suprema de Justicia de Colombia. Sentencia del 27 de octubre de 1914, M. P. Constantino Barco.

Corte Suprema de Justicia de Colombia. Sentencia del 30 de octubre de 1935, M. P. Antonio Rocha.

Corte Suprema de Justicia de Colombia. Sentencia del 5 de agosto de 1937, M. P. Juan Francisco Mujica.

Daryl Lim, Patent Misuse and Antitrust Law: Empirical, Doctrinal and Policy Perspectives, Edward Elgar Publishing Limited (2013).

Deborah Halbert, The politics of IP maximalism, 3 The WIPO Journal, n. ${ }^{\circ}$ 1, 81-92 (2011). https://www.wipo.int/ed ocs/pubdocs/en/intproperty/wipo_journal/wipo_journal_3_1.pdf

Decisión Andina 351 de 1993.

Decisión Andina 486 de 2000.

Eastman Kodak vs. Image Technical Servs, 504 U. S. 451 (1992).

Ernesto Rengifo, Del abuso del derecho al abuso de la posición dominante, Ed. Universidad Externado de Colombia (2. ${ }^{a}$ ed., 2004).

Fernando Zapata, El derecho de autor en el ámbito de la sociedad del conocimiento: desafíos y oportunidades, en La propiedad intelectual en los tratados comerciales: ¿oportunidad o carga para el mundo en desarrollo? Fundación Agenda Colombia, 183-188 (2005).

Gustavo Ordoqui Castilla, Abuso de derecho: civil, comercial, procesal, laboral y administrativo, Ed. Pontificia Universidad Javeriana \& Ibáñez (2010).

IMS Health GmbH \& Co OHG vs. NDC Health GmbH \& Co KG, Asunto: C-418/01 de 29 de abril de 2004. http://curia.europa.eu/juris/document/document.jsf?text $=\&$ docid $=49104 \&$ pageIndex $=0 \&$ doclang $=\mathrm{E}$ S\&mode $=1$ st $\&$ dir $=\&$ occ $=$ first $\&$ part $=1 \&$ cid $=14583793$

Ioannis Lianos, competition law and Intellectual Property (IP) rights: analysis, cases and materials, en Competition Law (Ioannis Lianos, Valentine Korah \& Paolo Siciliani eds., 2016). http://dx.doi.org/10.2139/ssrn.2863814

John Rodríguez, La evolución de la patentabilidad de material biológico en Estados Unidos y Europa: Patentes sobre descubrimientos y apropiación de la vida, Revista Jurídica Universidad Autónoma de Madrid, n. ${ }^{\circ}$ 17, 201-227 (2008). https://revistas.uam.es/revistajuridica/article/view/6099

Jorge Contreras, Origins of FRAND Licensing Commitments in the United States and Europe, en The Cambridge handbook of technical standardization law: Competition, antitrust and patents, (Jorge L. Contreras ed., 2017).

Juan Camilo Contreras-Jaramillo, Algunos problemas del agotamiento de los derechos de propiedad intelectual respecto de las licencias de software, Vniversitas, n. ${ }^{\circ} 132,111-132$ (2016). http://dx.doi.org/10.11144/Javeria na.vj132.apad

Juan Camilo Contreras-Jaramillo, El aparato teórico en la estructura tradicional del sistema de propiedad intelectual, Vniversitas, n. ${ }^{\circ} 135,99-130$ (2017). https://doi.org/10.11144/Javeriana.vj135.atet

Juan Pablo II, Solicitudo Rei Socialis. Carta Encíclica, promulgada el 30 de diciembre (1987). 
L. Peter Farkas, Can a patent still be misused? 59 Antitrust Law Journal, n. ${ }^{\circ}$ 3, 677-686 (1990). https://www.jstor.or $\mathrm{g} /$ stable/40841335

Leitch Manuf. Co. vs. Barber Co., 302 U.S. 458 (1938).

León Bourgeois, La solidarité, Presses Universitaires du Septentrión (1998).

Ley 1258 de 2008. Por medio de la cual se crea la sociedad por acciones simplificada. 5 de diciembre de 2008. D. O. n. 47194.

Ley 160 de 1994. Por la cual se crea el Sistema Nacional de Reforma Agraria y Desarrollo Rural Campesino, se establece un subsidio para la adquisición de tierras, se reforma el Instituto Colombiano de la Reforma Agraria y se dictan otras disposiciones. 9 de agosto de 1994. D. O. 41479.

Ley 1708 de 2014. Por medio de la cual se expide el Código de Extinción de Dominio. 20 de enero de 2014. D. O. 49039.

Ley 200 de 1936. Sobre régimen de tierras. 30 de diciembre de 1936. D. O. n. 23388.

Ley 23 de 1982. Sobre derechos de autor. 28 de enero de 1982. D. O. 35.949

Ley 388 de 1997. Por la cual se modifica la Ley $9^{a}$ de 1989, y la Ley $3^{\text {a }}$ de 1991 y se dictan otras disposiciones. 18 julio de 1997. D. O. 43127

Ley 4 de 1973. Por la cual se introducen modificaciones a las Leyes 200 de 1936, 135 de 1961 y $1^{\text {a de }} 1968$. Se establecen disposiciones sobre renta presuntiva, se crea la Sala Agraria en el Consejo de Estado y se dictan otras disposiciones. 29 de marzo de 1973. D. O. 33854.

Louis Josserand, Del abuso de los derechos y otros ensayos, Ed. Temis (2009).

Microsoft vs. Comisión de las Comunidades Europeas, Asunto T-201/04 de 17 de septiembre de 2007, Rec. Juris, I-5039 (2004).

Mikel Gómez Uranga, María del Socorro López Gómez \& Andrés Araujo de la Mata, Los ADPIC plus en los actuales tratados bilaterales impulsados por Estados Unidos y consecuencias en los paises en desarrollo, Revista de Economía Mundial, n. ${ }^{\circ}$ 20, 23-48 (2008).

Motion Picture Patents Co. vs. Universal Film Mfg. Co., 243 U.S. 502 (1917).

OECD, Licensing of IP rights and competition law, background note by the secretariat, 29 April 2019, DAF/ $\operatorname{COMP}(2019) 3(2019)$

Oil States Energy Services, LLC vs. Greene’s Energy Group, LLC, 584 U.S. (2018). https://www.supremecourt.gov /opinions/17pdf/16-712_87ad.pdf

Organización Mundial de la Propiedad Intelectual \& Comité de Desarrollo y Propiedad Intelectual (CDIP), Flexibilidades en materia de patentes en el Marco Jurídico Multilateral y su aplicación legislativa en los planos nacional y regional-parte III (2014).

Óscar Lizarazo-Cortés \& Natalia Lamprea Bermúdez, Implementación del Protocolo Acelerado de Patentes (PPH) en Colombia. Análisis jurídico, técnico y efectos iniciales, Revista Propiedad Inmaterial, n. ${ }^{\circ}$ 18, 281-321 (2014). http s://revistas.uexternado.edu.co/index.php/propin/article/view/3919

Radio Telefis Eireann vs. Commission (Magill), Asuntos Acumulados: C-241/91 P, de 6 de abril de 1995. http://curia.europa.eu/juris/showPdf.jsf?text=\&docid=98207\&pageIndex=0\&doclang=ES\&mode=lst \&dir $=\&$ occ $=$ first\&part $=1 \&$ cid $=14582636$

Robert J. Hoerner, Patent misuse: Portents for the 1990s, 59 Antitrust Law Journal, n. ${ }^{\circ} 3,687-716$ (1990). https://w ww.jstor.org/stable/40841336

Shashank P. Kumar, International trade, public health and intellectual property maximalism: the case of European border enforcement and trade in generic pharmaceuticals, 5 Global Trade and Customs Journal, n. ${ }^{\circ} 4,155-169$ (2010). $\mathrm{h}$ ttps://ssrn.com/abstract $=1564960$.

Superintendencia de Industria y Comercio, Concepto en relación con la solicitud de declaratoria de interés público del IMATINIB con fines de licencia obligatoria (2016). https://www.minsalud.gov.co/sites/rid/Lists/BibliotecaD igital/RIDE/VS/MET/subcomision-propiedad-industrial-definitiva-dnp.pdf

Superintendencia de Industria y Comercio, Resolución 40912 de 2012. 
Thomas F. Cotter, Misuse, 44 Houston Law Review, n. ${ }^{\circ}$ 4, 901-964 (2007).

TJUE, UsedSoft GmbH vs. Oracle International Corp., 3 de julio de 2012. http://curia.europa.eu/juris/document/ document.jsf?docid $=124564 \&$ doclang $=\mathrm{ES}$

Vanessa Jiménez Serranía, Consideraciones en torno al posible abuso de posición dominante de las entidades de gestión de derechos de autor y derechos conexos en el establecimiento de sus tarifas comentario sobre la STJCE, de 11 de diciembre de 2008, asunto Kanal 5 LDT y otros contra Föreningen Svenska Tonsättares Internationella Musikbyra (STIM) u.p.a. (entidad sueca de gestión colectiva de derechos), (C-52/07), Revista General de Derecho Europeo, n. 19 (2009). https://www.iustel.com/v2/revistas/detalle_revista.asp?id_noticia $=408263$

Vanessa Jiménez Serranía, El control de las entidades de gestión por las autoridades de defensa de la competencia: tarifas y acuerdos de reciprocidad, los grandes caballos de batalla (reflexiones a partir de la sentencia del TJCE de 23 de abril de 2009 en el asunto "C-425/07"), Actas de Derecho Industrial y Derecho de Autor, n. 29 , 929-948 (2008-2009).

Volvo vs. Veng, Asunto: C-238/87 de 5 de octubre de 1988. https://eur-lex.europa.eu/resource.html?uri=cellar:24c3 3700-2092-4e4b-abc6-ed97a2b159ce.0008.03/DOC_2\&format=PDF

\section{Notas}

* Artículo de investigación. Resultado del proyecto de investigación "Límites y Restricciones a la Propiedad", ID 00006566, de la Pontificia Universidad Javeriana

[1] En este sentido encontramos cómo las regulaciones nacionales han aumentado sus niveles de protección, más allá de que los acuerdos internacionales en la materia les demandan, normas conocidas como "ADPIC o TRIPS plus"; ver: Mikel Gómez Uranga, María del Socorro López Gómez \& Andrés Araujo de la Mata, Los ADPIC plus en los actuales tratados bilaterales impulsados por Estados Unidos y consecuencias en los países en desarrollo, Revista de Economía Mundial, n. ${ }^{\circ} 20,23-48$ (2008). Sobre el fenómeno del maximalismo, ver: Deborah Halbert, The politics of IP maximalism, 3 The WIPO Journal, n. ${ }^{0}$ 1, 81-92 (2011); Shashank P. Kumar, International trade, public health and intellectual property maximalism: the case of European border enforcement and trade in generic pharmaceuticals, 5 Global Trade and Customs Journal, n. ${ }^{\circ} 4,155-169$ (2010). Proceso de expansión de los derechos de propiedad intelectual que se evidencia en la protección de las plantas y el material vivo. Ver: Ángel García Vidal, El material vegetal protegido por una patente o un derecho de obtentor y el empleo del producto de su cosecha con fines de propagación: agotamiento y privilegio del agricultor en Europa y en los EE.UU., 8 Cuadernos de Derecho Transnacional, n. ${ }^{\circ}$ 1, 76-100 (2016). También ver: Organización Mundial de la Propiedad Intelectual \& Comité de Desarrollo y Propiedad Intelectual (CDIP), Flexibilidades en materia de patentes en el Marco Jurídico Multilateral y su aplicación legislativa en los planos nacional y regional-parte III (2014). Sobre otros temas: John Rodríguez, La evolución de la patentabilidad de material biológico en Estados Unidos y Europa: Patentes sobre descubrimientos y apropiación de la vida, Revista Jurídica Universidad Autónoma de Madrid, n. ${ }^{\circ}$ 17, 201-227 (2008); Óscar Lizarazo-Cortés \& Natalia Lamprea Bermúdez, Implementación del Protocolo Acelerado de Patentes (PPH) en Colombia. Análisis jurídico, técnico y efectos iniciales, Revista Propiedad Inmaterial, n. ${ }^{\circ} 18,281-321$ (2014). En este mismo sentido encontramos cómo las regulaciones nacionales han aumentado sus niveles de protección más allá de que los acuerdos internacionales en la materia les demandan, normas conocidas como "ADPIC o TRIPS plus"; ver: Mikel Gómez Uranga, María del Socorro López Gómez \& Andrés Araujo de la Mata, op. cit.

[2] Carlos Andrés Uribe Piedrahita, La innovación subsiguiente como límite económico para la valoración del comportamiento de abuso de posición dominante relacionado con las negativas a contratar o licenciar, Vniversitas, n. ${ }^{\circ}$ 126, 269-298 (2013).

[3] Sobre la historia del licenciamiento FRAND ver, Jorge Contreras, Origins of FRAND Licensing Commitments in the United States and Europe, en The Cambridge handbook of technical standardization law: Competition, antitrust and patents, (Jorge L. Contreras ed., 2017).

[4] Para ahondar en casos que ejemplifican esta situación, ver: Vanessa Jiménez Serranía, El control de las entidades de gestión por las autoridades de defensa de la competencia: tarifas y acuerdos de reciprocidad, los grandes caballos de batalla (reflexiones a partir de la sentencia del TJCE de 23 de abril de 2009 en el asunto "C-425/07"), Actas de Derecho Industrial y Derecho de Autor, n. 29 , 929-948 (2008-2009); Vanessa Jiménez Serranía, Consideraciones en torno al posible abuso de posición dominante de las entidades de gestión de derechos de autor y derechos conexos en el establecimiento de sus tarifas comentario sobre la STJCE, de 11 de diciembre de 2008, asunto Kanal 5 LDT y otros contra Föreningen Svenska Tonsättares Internationella Musikbyra (STIM) u.p.a. (entidad sueca de gestión colectiva de derechos), (C-52/07), Revista General de Derecho Europeo, n. 19, (2009). 
[5] Reconocer la posibilidad de licencias obligatorias desde el derecho de la competencia no puede distraer la atención sobre la excepcionalidad de esta intervención. La imposición de licencias obligatorias tiene consecuencia sobre la propiedad intelectual que afecta los presupuestos que justifican su existencia, esto es, pone en riesgo los incentivos para innovar que se atribuyen a la propiedad intelectual. Se deriva de lo anterior el riesgo sobre el valor de mercado de dicha propiedad y los beneficios esperados que se puedan derivar de la misma, al igual la capacidad del titular de limitar el número de agentes que puedan gozar de dichos de derechos. Ver: Carl Shapiro \& David Teece, Systems Competition and Aftermarkets: An Economic Analysis of "Kodak", 39 The Antitrust Bulletin, n. ${ }^{\circ} 1,135-162$ (1994); Carl Shapiro, Aftermarkets and consumer welfare: making sense of Kodak, 63 Antitrust Law Journal, n. ${ }^{\circ}$ 2, $483-511$ (1995); Carlos Andrés Uribe Piedrahita, Elpoder de mercado en los aftermarkets: Consideraciones sobre lapolitica de competencia en los mercados secundarios, Revista de derecho de la competencia y la distribución, n. ${ }^{\circ}$ 10, 129-160 (2012); Carlos Andrés Uribe Piedrahita, Cuestiones concurrenciales y marcarias en la distribución depiezas de recambio (la problemática de los "aftermarkets"), en Marcas y distribución comercial 213-268 (Eduardo Galán Corona \& Fernando Carbajo Cascón coords., 2011); OECD, Licensing of IP rights and competition law, background note by the secretariat, 29 April 2019, DAF/COMP(2019)3, 31-32 (2019); Ioannis Lianos, competition law and Intellectual Property (IP) rights: analysis, cases and materials, en Competition Law (Ioannis Lianos, Valentine Korah \& Paolo Siciliani eds., 2016).

[6] Decisiones de la Unión Europea relacionados con negativas a contratar, se encuentran: Volvo vs. Veng, Asunto: C-238/87 de 5 de octubre de 1988; Radio Telefis Eireann vs. Commission (Magill), Asuntos Acumulados: C-241/91 P, de 6 de abril de 1995; Sentencia del Tribunal de Justicia, IMS Health GmbH \& Co OHG vs. NDC Health GmbH \& Co KG, Asunto: C-418/01 [2004] ECR I-5039; Microsoft vs. Comisión de las Comunidades Europeas, Asunto T-201/04 de 17 de septiembre de 2007, Rec. Juris, I-5039 (2004). En estados Unidos: Eastman Kodak vs. Image Technical Servs, 504 U. S. 451 (1992).

[7] Sobre el caso icónico en el que se determinó la existencia del agotamiento de los derechos de propiedad intelectual, a pesar de lo dispuesto originalmente en el contrato por parte del titular, ver: TJUE, UsedSoft GmbH vs. Oracle International Corp., 3 de julio de 2012. Y para otros casos relacionados ver: Juan Camilo Contreras-Jaramillo, El aparato teórico en la estructura tradicional del sistema de propiedad intelectual, Vniversitas, n. ${ }^{\circ}$ 135, 99-130 (2017).

[8] Fue finalmente decidido por la Corte Suprema de Justicia de los Estados Unidos, Oil States Energy Services, LLC vs. Greene's Energy Group, LLC, 584 U.S. (2018).

[9] Adam Mossoff, Statutes, common-law rights, and the mistaken classification of patents as public rights, 104 Iowa Law Review, n. ${ }^{\circ} 5,2591-2616$.

[10] Superintendencia de Industria y Comercio, Concepto en relación con la solicitud de declaratoria de interés público del IMATINIB con fines de licencia obligatoria (2016). https://www.minsalud.gov.co/sites/rid/Lists/BibliotecaDigital/RIDE/VS/ MET/subcomision-propiedad-industrial-definitiva-dnp.pdf

[11] Fernando Zapata, El derecho de autor en el ámbito de la sociedad del conocimiento: desafios y oportunidades, en La propiedad intelectual en los tratados comerciales: ¿oportunidad o carga para el mundo en desarrollo? Fundación Agenda Colombia, 183-188 (2005).

[12] Corte Constitucional de Colombia. Sentencia C-276 de 1996 (M. P. Julio Cesar Ortiz; 20 de junio de 1996).

[13] En este punto hacemos referencia a una acepción de límite referida a los casos en que algunos derechos de propiedad intelectual son restringidos, sin que se deje de reconocer la existencia de la titularidad de los mismos. De tal manera, la acepción de límite que utilizamos excluye aquellos casos en que el derecho de propiedad intelectual no es reconocido, es decir, lo que podría denominarse como una excepción.

[14] Decisión Andina 486, artículo 53.

[15] Decisión Andina 351 de 1993, artículo 22.

[16] Decisión Andina 486, artículo 157.

[17] Ley 23 de 1982. Sobre derechos de autor. 28 de enero de 1982.

[18] Carlos Andrés Uribe Piedrahita \& Fernando Carbajo Cascón, Regulación "ex ante" y control "expost": la difícil relación entre propiedad intelectual y derecho de la competencia, Actas de derecho industrial y derecho de autor, n. ${ }^{\circ} 33,307-330$ (2012-2013).

[19] En Colombia con toda claridad se les atribuye el origen a las sentencias de la Corte Suprema de Justicia - tales como la sentencia del 30 de octubre de 1935, M. P. Antonio Rocha; Sentencia del 5 de agosto de 1937, M. P. Juan Francisco Mujica; u otras en donde la referencia resulta indirecta como la sentencia del 27 de octubre de 1914, M. P. Constantino Barco. En este sentido ver: 
Carlos Ignacio Jaramillo, El 'abuso del derecho' y su proyección en los ámbitos sustancial y procesal civil: perfiles de la conducta abusiva e inobservancia del deber de obrar de buena fe, Ed. Pontificia Universidad Javeriana \& Ibáñez, 106 (2019). Por su parte Josserand dio crédito al origen romano de este principio, haciendo referencia a las máximas summum ius, summa iniuria y male enim nostro iure uti nom debemus. Louis Josserand, Del abuso de los derechos y otros ensayos, Ed. Temis, 5 (2009). Posición que controvierte gran parte de doctrina; ver: Ernesto Rengifo, Del abuso del derecho al abuso de la posición dominante, Ed. Universidad Externado de Colombia, 41 (2.a ed., 2004). Otros fijan su origen en la jurisprudencia francesa de finales del siglo XIX, ver: Gustavo Ordoqui Castilla, Abuso de derecho: civil, comercial, procesal, laboral y administrativo, Ed. Pontificia Universidad Javeriana \& Ibáñez, 33 (2010).

[20] Carlos Ignacio Jaramillo, op. cit., 89.

[21] Corte Suprema de Justicia de Colombia. Sentencia del 5 de agosto de 1937, M. P. Juan Francisco Mujica.

[22] Tal y como se puede encontrar en: (i) el artículo 95 de la Constitución Política de Colombia; (ii) el artículo 830 del Código de Comercio Colombiano; (iii) el artículo 43 de la Ley 1258 de 2008; entre otros. Y como también puede ser verificado en otros ordenamientos jurídicos como Argentina, España, Italia o Perú. Ver, Carlos Ignacio Jaramillo, op. cit., 99.

[23] Juan Camilo Contreras-Jaramillo, El aparato teórico en la estructura tradicional del sistema de propiedad intelectual, Vniversitas, n. ${ }^{\circ} 135,99-130$ (2017).

[24] Ver supra nota 18.

[25] Aunque se reconocen diferentes posiciones al respecto, el presente artículo responde a esta visión dentro del sistema jurídico colombiano. En tal sentido ver: Corte Suprema de Justicia de Colombia. Sala Plena. Sentencia del 10 de febrero de 1960, M. P. Humberto Barrera Domínguez; Corte Constitucional de Colombia. Sentencia C-334-93 de 1993 (M. P. Alejandro MartínezCaballero; 12 de agosto de 1993). Corte Constitucional de Colombia. Sentencia C-148-15 de 2015 (M. P. Gloria Stella OrtizDelgado; 7 de abril de 2015); Juan Camilo Contreras-Jaramillo, El aparato teórico (...), op. cit.

[26] Tal y como expresamente lo señalan los artículos 58 de la Constitución Nacional y 669 del Código Civil.

[27] En este sentido, ver, entre otras: Corte Constitucional de Colombia. Sentencia T-506 de 1992 (M. P. Ciro Angarita Barón; 22 de agosto de 1992); Corte Constitucional de Colombia. Sentencia T-413 de 1997 (M. P. José Gregorio Hernández Galindo; 28 de agosto de 1997); Corte Constitucional de Colombia. Sentencia T-554 de 1998 (M. P. Fabio Morón Díaz; 5 de octubre de 1998). Corte Constitucional de Colombia. Sentencia T-947 de 2001 (M. P. Manuel José Cepeda Espinosa; 4 de septiembre de 2001); Corte Constitucional de Colombia. Sentencia T-016 de 2009 (M. P. Jaime Córdoba Triviño; 23 de enero de 2009).

[28] En este sentido, ver entre otras, Corte Suprema de Justicia de Colombia. Sala de Casación Civil. Sentencia de fecha 6 de diciembre de 1899, Gaceta Judicial Año 15, 8; Corte Suprema de Justicia de Colombia. Sala de Negocios Generales. Sentencia de fecha 6 de mayo de 1927, Gaceta Judicial, año 34, 264 y Corte Constitucional de Colombia. Sentencia C-595 de 1999 (M. P. Carlos Gaviria Díaz; 18 de agosto de 1999), Acción de Constitucionalidad contra el artículo 669 del Código Civil.

[29] León Bourgeois, La solidarité, Presses Universitaires du Septentrión (1998).

[30] Juan Pablo II, Solicitudo Rei Socialis. Carta Encíclica, promulgada el 30 de diciembre (1987).

[31] La Corte Constitucional ha definido dicha figura como aquel "deber -impuesto a toda persona por el sólo hecho de su pertenencia al conglomerado social- consistente en la vinculación del propio esfuerzo y actividad en beneficio o apoyo de otros asociados o en interés colectivo". Corte Constitucional de Colombia. Sentencia T-550 de 1994 (M. P. José Gregorio Hernández Galindo; 2 de diciembre de 1994); Adicional a la anterior ver entre otras: Corte Constitucional de Colombia. Sentencia T-073 de 1998 (M. P. Vladimiro Naranjo Mesa; 9 de marzo de 1998); Corte Constitucional de Colombia. Sentencia T-801 de 1998 (M. P. Eduardo Cifuentes Muñoz; 16 de diciembre de 1998); Corte Constitucional de Colombia. Sentencia T-434 de 2002 (M. P. Rodrigo Escobar Gil; 30 de mayo de 2002); Corte Constitucional de Colombia. Sentencia C-1054 de 2004 (M. P. Marco Gerardo Monroy Cabra; 26 de octubre de 2004).

[32] Consagrada en los artículos $6^{\circ}$ de la Ley 200 de 1936. Sobre régimen de tierras. 30 de diciembre de 1936. D. O. n..$^{\circ} 23388$; $3^{\circ}$ de la Ley 4 de 1973. Por la cual se introducen modificaciones a las Leyes 200 de 1936, 135 de 1961 y $1^{\text {a }}$ de 1968 . Se establecen disposiciones sobre renta presuntiva, se crea la Sala Agraria en el Consejo de Estado y se dictan otras disposiciones. 29 de marzo de 1973. D. O. 33854 y 52 a 64 de la Ley 160 de 1994. Por la cual se crea el Sistema Nacional de Reforma Agraria y Desarrollo Rural Campesino, se establece un subsidio para la adquisición de tierras, se reforma el Instituto Colombiano de la Reforma Agraria y se dictan otras disposiciones. 9 de agosto de 1994. D. O. 41479. 
[33] Consagrada en la Ley 1708 de 2014. Por medio de la cual se expide el Código de Extinción de Dominio. 20 de enero de 2014. D. O. 49039.

[34] Figura derogada y hoy sustituida para los mismos efectos por la enajenación forzosa consagrada en el Capítulo VI de la Ley 388 de 1997. Por la cual se modifica la Ley $9^{a}$ de 1989, y la Ley $3^{a}$ de 1991 y se dictan otras disposiciones. 18 julio de 1997. D. O. 43127

[35] Entre otras Corte Suprema de Justicia de Colombia. Sala plena. Sentencia de fecha 10 de marzo de 1938, M. P. Hernán Guillermo Aldana Duque, 140; Corte Constitucional de Colombia. Sentencia C-006 de 1993 (M. P. Eduardo Cifuentes Muñoz; 18 de enero de 1993; Corte Constitucional de Colombia. Sentencia T-431 del 30 de septiembre de 1994 (M. P. José Gregorio Hernández Galindo; 30 de septiembre de 1994), Sentencia citada y Corte Constitucional de Colombia. Sentencia C-666 de 2010 (M. P. Humberto Antonio Sierra Porto; 30 de agosto de 2010), Acción de inconstitucionalidad contra el artículo $7^{\circ}$ de la Ley 84 de 1989.

[36] Ernesto Rengifo, op. cit., 75 .

[37] Corte Constitucional de Colombia. Sentencia T-511 de 1993 (M. P. Eduardo Cifuentes Muñoz; del 8 de noviembre de 1993).

[38] Dentro de una economía de mercado cuyas libertades están razonablemente limitados. Ver, Corte Constitucional de Colombia Sentencia C-228 de 2010 (M. P. Luis Ernesto Vargas Silva; 24 de marzo de 2010); Artículo 333. Constitución Política de Colombia.

[39] Corte Constitucional de Colombia. Sentencia C-830 de 2010, consideración jurídica n. 3 3 (M. P. Luis Ernesto Vargas Silva; 20 de octubre de 2010); Corte Constitucional de Colombia Sentencia C-228 de 2010 (M. P. Luis Ernesto Vargas Silva; 24 de marzo de 2010); Corte Constitucional de Colombia. Sentencia C-428 de 2007 (M. P. Jose Gregorio Hernández Galindo, Alejandro Martinez Caballero y Vladimiro Naranjo Mesa; xx de xxx de 2007); Corte Constitucional de Colombia. Sentencia T-533 de 1992 (M. P. Eduardo Cifuentes Muñoz; 23 de septiembre de 1992); Corte Constitucional de Colombia. Sentencia C-978 de 2010 (M. P. Luis Ernesto Vargas Silva; 1 ro de diciembre de 2010): "El aseguramiento de la concurrencia en el mercado [...], debe llevarse a cabo bajo la premisa de la garantía de la calidad del servicio y de su efectiva prestación y no sólo de la protección del lucro individual de los agentes privados. Ello es así por cuanto la libre competencia en Colombia se desarrolla dentro de una economía social de mercado, en la que existe la libre iniciativa privada, pero en la que a su vez el Estado se presenta como instrumento de justicia social ejerciendo cierta intervención redistributiva de la riqueza y de los recursos para corregir las desigualdades sociales originadas por los excesos individuales o colectivistas. Para preservar los valores superiores el Estado puede regular cualquier actividad económica libre introduciendo excepciones y restricciones sin que por ello pueda decirse que sufran menoscabo las libertades básicas que garantizan la existencia de la libre competencia. Por otro lado, dichas regulaciones sólo pueden limitar la libertad económica cuando y en la medida en que, de acuerdo con los principios de razonabilidad y proporcionalidad, ello sea necesario para la protección de los valores superiores" (notas fuera del texto).

[40] Corte Constitucional de Colombia. Sentencia C-992 de 2006 (M. P. Álvaro Tafur Galvis; 29 de noviembre de 2006); Corte Constitucional de Colombia. Sentencia C-1231 de 2005 (M. P. Manuel José Cepeda Espinosa; 29 de noviembre de 2005).

[41] Superintendencia de Industria y Comercio, Resolución 40912 de 2012, $45-58$ (2012).

[42] Corte Suprema de Justicia de Colombia. Sala Plena. Sentencia del 10 de febrero de 1960, M. P. Humberto Barrera Domínguez.

[43] Los titulares de derechos de propiedad intelectual tienen una libertad considerable para decidir las condiciones bajo las cuales se pueden dar los intercambios de su tecnología patentada, de las obras protegidas por el derecho de autor y demás bienes que incorporan la propiedad intelectual.

[44] Daryl Lim, Patent Misuse and Antitrust Law: Empirical, Doctrinal and Policy Perspectives, Edward Elgar Publishing Limited, 19 (2013).

[45] Íd., 7

[46] L. Peter Farkas, Can a patent still be misused? 59 Antitrust Law Journal, n. ${ }^{3}$, 677 (1990).

[47] Robert J. Hoerner, Patent misuse: Portents for the 1990s, 59 Antitrust Law Journal, n. ${ }^{\circ}$ 3, 687-716 (1990)

[48] Thomas F. Cotter, Misuse, 44 Houston Law Review, n. ${ }^{\circ} 4,934,935$ (2007). 
[49] Daryl Lim, op. cit., 26

[50] Íd., 26

[51] Motion Picture Patents Co. vs. Universal Film Mfg. Co., 243 U.S. 502 (1917).

[52] Íd., 516. Traducción de los autores.

[53] Íd., 513. Sostiene la Corte en Motion Pictuares que los titules de derechos de propiedad intelectual no deben buscar la obtención de mayores rentas a través de imponer restricciones por medio de contratos u otros instrumentos jurídicos que limitan el bienestar de la sociedad con el fin de obtener mejores rentas. "Si su descubrimiento es importante, su recompensa bajo el derecho será grande, como la experiencia lo ha demostrado suficientemente y si no es importante, los dispositivos legales no deberían permitirle imponer una carga injusta sobre el público para el uso de esta".

[54] Christina Bohannan \& Herbert Hovenkamp, Creation without restraint. Promoting liberty and rivalry in innovation, Oxford University Press 267 (2012).

[55] Traducción libre del disenso del Juez Holmes en el asunto Motion Picture Patents Co. vs. Universal Film Mfg. Co., 243 U.S. 502 (1917).

[56] Corte Suprema de Justicia de Colombia. Sala de casación civil. Sentencia de 15 de noviembre de 2013. M. P. Arturo Solarte Rodríguez; Corte Suprema de Justicia de Colombia. Sala de casación civil. Sentencia 125 de 1994. M. P. Carlos Esteban Jaramillo Schloss; 19 de octubre de 1994); Corte Suprema de Justicia de Colombia. Sala de casación civil. Sentencia de 16 de septiembre de 2010. M. P. César Julio Valencia Copete.

[57] Íd.

[58] Christina Bohannan \& Herbert Hovenkamp, op. cit., 261-262.

[59] Carbice Corp. vs. Patents Development Corp., 283 U.S. 27, 32 (1931).

[60] Carbice Corp. vs. Patents Development Corp., 283 U.S. 27, 33 (1931).

[61] Esta forma de análisis y desarrollo de la doctrina del misuse fue aplicada en el asunto Leitch Manuf. Co. vs. Barber Co., 302 U.S. 458 (1938).

\section{Licencia Creative Commons CC BY 4.0}

Para citar este articulo/To cite this article: Felipe Arbouin-Gómez, Juan camilo Contreras-Jaramillo \& Carlos Andrés Uribe-Piedrahita, La aplicación de la función social de la propiedad intelectual a través del abuso del derecho: un análisis necesario para el sistema de derecho civil, 68 Vniversitas, n. ${ }^{\circ} 139$ (2019). https://doi.org //10.11144/Javeriana.vj139.afsp 